ÉESTI NSV TEADUSTE AKADEEMIA TOIMETISED. KEEMIÁ

ИЗВЕСТИЯ АКАДЕМИИ НАУК ЭСТОНСКОП ССР. ХИМИЯ

PROCEEDINGS OF THE ACADEMY OF SCIENCES OF THE ESTONIAN SSR. CHEMISTRY

$1988,37,4$

УДК 553.983.002.61 : 543.82

В. ВЫСОЦКАЯ, К. УРОВ

\title{
ВЛИЯНИЕ ПИРИТА НА ВЫХОД И СОСТАВ ПРОДУКТОВ ПОЛУ- КОКСОВАНИЯ ГОРЮЧИХ СЛАНЦЕВ
}

\section{1. ДИКТИОНЕМОВЫЙ СЛАНЕЦ ЭССР}

\author{
(Представил О. Киррет)
}

В продолжение серии работ по уяснению воздействия минеральных веществ различного типа на процесс термического разложения органического вещества (ОВ) кукерсита и диктионемового сланца ЭССР $\left[{ }^{1-4}\right]$ в настоящем исследовании изучено влияние всегда присутствующего в горючих сланцах пирита на выход и состав продуктов полукоксования указанных сланцев.

Имеются данные о каталитическом влиянии пирита в процессах ожижения и гидрогенизации углей $\left[{ }^{5-8}\right]$. При исследовании влияния минеральных веществ на термическую деструкцию горючего сланца месторождения Грин Ривер (США) [9] с использованием различных фракций сланца, содержащих $0,5-3,4 \%$ пирита, достаточной ясности относительно роли этого минерала достигнуто не было.

В настоящей работе влияние пирита на термическое разложение ОВ диктионемового сланца месторождения Тоолсе исследовали с использованием искусственных смесей, составлявшихся из пиритного концентрата и концентрата керогена * (табл. 1), полученных при флотационном обогащении этого сланца. Содержание пирита определяли комплексометрически по железу.

Полукоксование модельных смесей, содержание условной органической массы в которых составляло от 13,5 до $68,8 \%$ (табл. 2), проводили в лабораторной алюминиевой реторте с электрообогревом по температурному режиму ГОСТа 3168-66. Обесфеноленные смолы разделяли методом тонкослойной хроматографии (силикагель, $н$-гексан) на групповые компоненты, состав которых, равно как и состав газообразных продуктов, исследовали газохроматографически.

Данные о выходе и составе продуктов полукоксования приведены в табл. $2-4$ и на рис. $1-3$.

\begin{tabular}{|c|c|c|}
\hline Компонент & $\begin{array}{r}\text { Пиритный } \\
\text { концентрат }\end{array}$ & $\begin{array}{c}\text { Концентрат } \\
\text { органиче- } \\
\text { ского } \\
\text { вещества }\end{array}$ \\
\hline $\begin{array}{l}\mathrm{FeS}_{2} \\
\mathrm{SiO}_{2} \\
\mathrm{Al}_{2} \mathrm{O}_{3} \\
\mathrm{CaO} \\
\mathrm{MgO} \\
\mathrm{K}_{2} \mathrm{O} \\
\mathrm{Na}_{2} \mathrm{O} \\
\mathrm{TiO}_{2} \\
\mathrm{SO}_{3}\end{array}$ & $\begin{array}{r}95,2 \\
1,1 \\
2,3 \\
0,0 \\
0,1 \\
0,1 \\
2,2 \\
0,1 \\
0,3\end{array}$ & $\begin{array}{r}7,2 \\
21,9 \\
5,7 \\
0,1 \\
0,7 \\
1,9 \\
0,1 \\
0,5 \\
1,9\end{array}$ \\
\hline$A^{d}$ & 65,6 & 29,7 \\
\hline
\end{tabular}

* Анализ концентратов проведен Е. Клаос 
Характеристика исходных модельных смесей и выход из них продуктов полукоксования, \%

\begin{tabular}{l|l|l|l|l|l|l|l|l|l}
\hline \multirow{2}{*}{ Показатель } & \multicolumn{10}{|c}{ Номер опыта } \\
\cline { 2 - 6 } & 1 & 2 & 3 & 4 & 5 & 6 & 7 \\
\hline
\end{tabular}

Исходные смеси:

$\begin{array}{lrrrrrrr}\text { Wa } & 1,8 & 1,8 & 2,2 & 2,2 & 2,1 & 2,4 & 2,0 \\ A^{d} & 61,6 & 58,0 & 52,8 & 46,5 & 40,3 & 34,9 & 29,7 \\ S_{t}^{d} & 39,9 & 35,5 & 30,8 & 24,9 & 16,7 & 10,0 & 2,7 \\ \begin{array}{l}\text { условная органическая } \\ \text { масса * }\end{array} & 13,5 & 19,8 & 27,9 & 37,9 & 49,3 & 58,8 & 68,8 \\ \begin{array}{l}\text { Выход продуктов полу- } \\ \text { коксования на сухую смесь: }\end{array} & & & & & & & \\ \begin{array}{l}\text { смола } \\ \text { вода пирогенетическая }\end{array} & 0,5 & 2,1 & 5,0 & 8,7 & 12,6 & 15,2 & 18,6 \\ \text { твердый остаток } & 2,7 & 3,3 & 4,2 & 5,1 & 2,9 & 4,7 & 6,3 \\ \text { газ+потери (по разности) } & 93,2 & 89,3 & 83,6 & 77,0 & 71,5 & 68,5 & 64,7 \\ & 3,6 & 5,3 & 7,2 & 9,2 & 13,0 & 11,6 & 10,4\end{array}$

\begin{abstract}
* Поскольку карбонаты в исходных компонентах отсутствовали, а содержание серы в золах составляло от 0 до $0,2 \%$ (т. е. пиритная сера практически полностью удалялась при озолении в виде $\mathrm{SO}_{2}$ ), то содержание условной органической массы определяли по упрощенной формуле Крыма $\left[{ }^{10}\right]\left(100-A^{d}-0,625 \quad S_{t}^{d}\right)$.
\end{abstract}

Выход смолы полукоксования в расчете на кероген снижается по мере уменьшения содержания ОВ в смеси (рис. 1), т. е. в этом отношении пирит влияет аналогично карбонатам [2] и алюмосиликатам $\left[{ }^{1}\right]$ : при увеличении содержания минеральных веществ возрастает доля смолы (особенно ее наиболее полярных компонентов), удерживаемой на поверхности твердого остатка и подвергающейся вторичной деструкции с формированием дополнительного количества несмоляных продуктов. Действительно, выход газа полукоксования при этом возрастает (рис. 1). K интерпретации. более сложных зависимостей выхода пирогенетической воды и твердого остатка разложения от содержания ОВ в смеси обратимся позднее.

На химический состав смол полукоксования пирит влияет также подобно карбонатным и глинистым породам, т. е. с возрастанием его содержания в смеси смола обогащается углеводородами (УВ), особенно наименее полярными парафино-нафтеновыми, за счет гетероатомных соединений, выход которых на кероген снижается особенно резко при относительно постоянном выходе неароматических УВ (рис. 2). Интересно, однако, что плотность смолы при этом возрастает (табл. 3); в этом аспекте пирит влияет на пиролиз керогена по-иному, чем карбонаты и алюмосиликаты $\left[{ }^{1,2}\right]$.

Что касается индивидуального химического состава смолы, то присутствие пирита не вызывает в нем существенных изменений, несколько меняется лишь количественное соотношение отдельных компонентов. Так, с увеличением содержания пирита в исходной смеси состав конденсированных ароматических УВ несколько облегчается (величина концентрационных отношений 2-метилнафталин:дифенил и 2-метилнафталин : флуорен возрастает соответственно с 1,03 и 1,00 в опыте 5 до 1,48 и 1,12 в опыте 2), тогда как состав фенолов утяжеляется (величина концентрационных отношений $о$-крезол : 1- и 2-нафтолы и $о$-крезол : метилнафтолы уменьшается соответственно с 6,0 и 4,3 в опыте 5 до 2,7 и 2,3 в опыте 2). С возрастанием концентрации пирита в смеси повышается величина отношения пристан: фитан (с $0,64-0,66$ в опытах $4-7$ до $0,88-0,98$ в опытах $1-3)$, что указывает на более глубокую деструкцию смолы в присутствии большого количества пирита. 


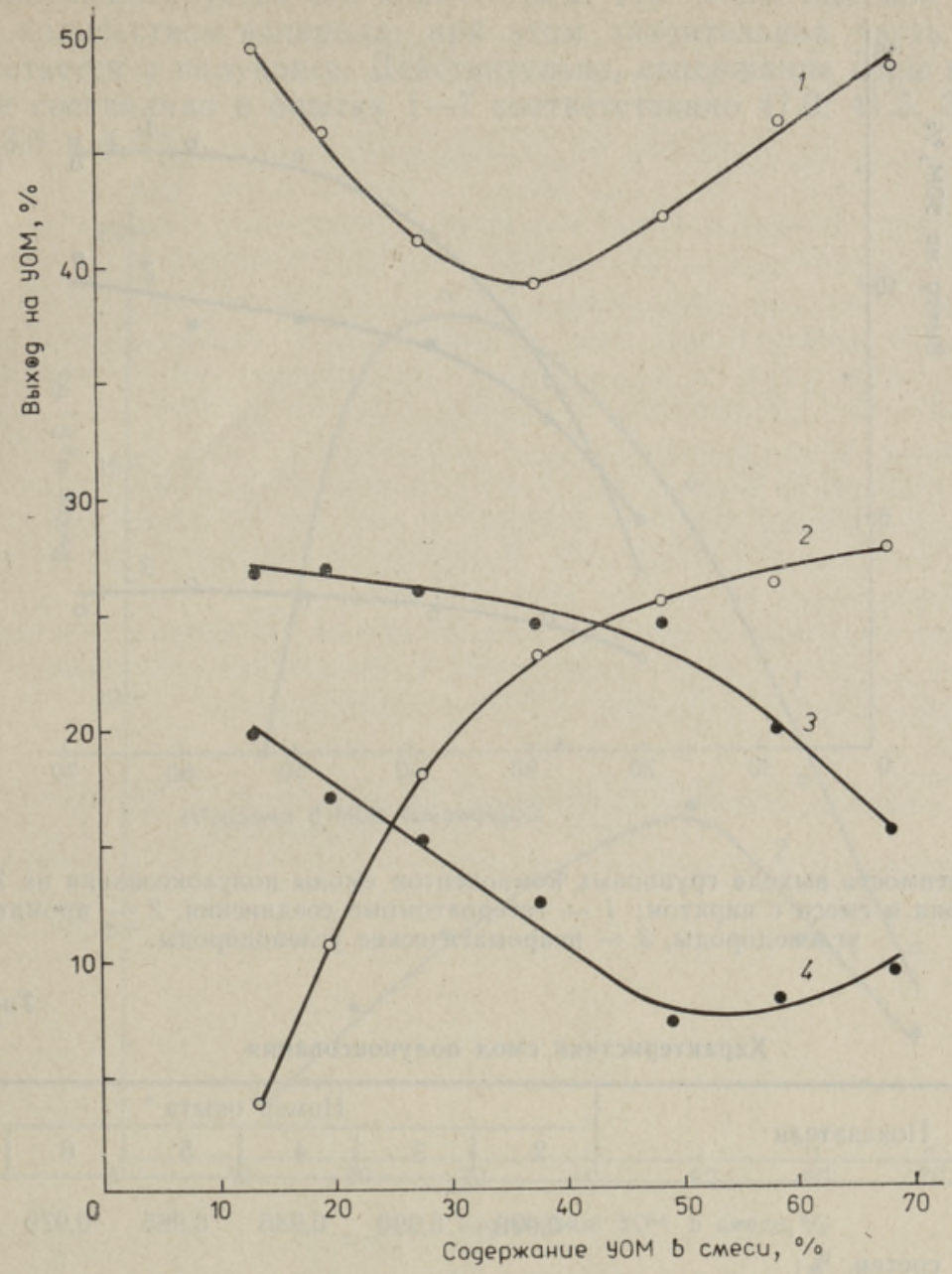

Рис. 1. Зависимость выхода продуктов полукоксования на условную органическую массу (УОМ, здесь и на рис. 2,3$)$ от ее содержания в смеси с пиритом: 1 - твердый остаток разложения, 2 - смола, 3 - газообразные продукты, 4 - пирогенетическая вода.

В формировании серусодержащих соединений сланцевой смолы пиритная сера принимает ограниченное участие; это следует из относительно низкого содержания серы в полученных смолах (табл. 3).

Роль пирита в процессе термической деструкции сланца заключается, наряду с подавлением смолообразования, также в генерации дополнительного количества сероводорода. Так, выход последнего достигает $19 \%$ на ОВ сланца; содержание серы в использованном концентрате керогена составляло $2,7 \%$ (табл. 2), и даже при ее полном удалении в виде сероводорода его выход на ОВ не может превышать $4,2 \%$ (в действительности же основная часть серы остается в полукоксе). Интенсивная восстановительная депиритизация твердого остатка имеет место также при полукоксовании узбекских нижнеэоценовых сланцев [ $\left.{ }^{11}\right]$.

Понятно, что расходование необходимого для формирования смолы водорода на образование сероводорода в свою очередь отрицательно влияет на выход смолы и сводит на нет возможный положительный каталитический эффект пирита. 


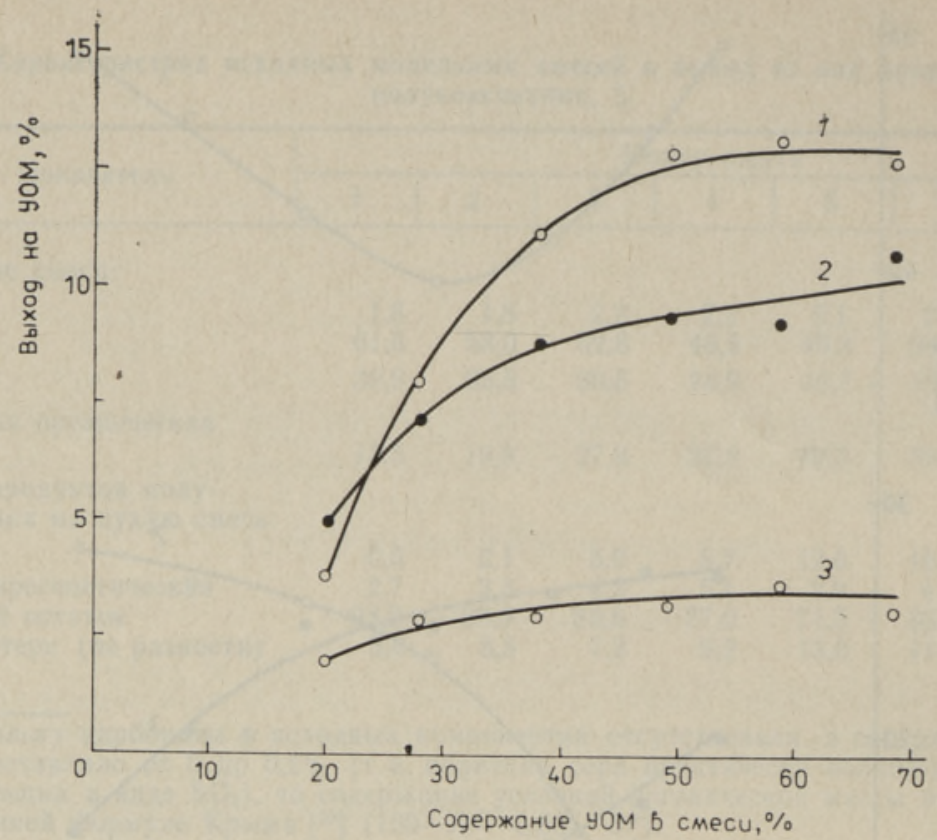

Рис. 2. Зависимость выхода групповых компонентов смолы полукоксования на УОМ от ее содержания в смеси с пиритом: 1 - гетероатомные соединения, 2 - ароматические углеводороды, 3 - неароматические углеводороды.

Таблица 3

Характеристика смол полукоксования

\begin{tabular}{l|r|r|r|r|r|r}
\hline \multirow{2}{*}{ Показатели } & \multicolumn{7}{c}{ Номер опыта * } \\
\cline { 2 - 7 } & 2 & 3 & 4 & 5 & 6 & 7 \\
\hline Плотность & 0,995 & 0,990 & 0,986 & 0,985 & 0,979 & 0,950 \\
Элементный состав, \%: & 79,9 & 81,0 & 82,0 & 81,2 & - & 83,1 \\
C & 8,6 & 8,7 & 8,9 & 9,1 & - & 9,2 \\
H & 3,9 & 4,1 & 3,5 & 3,7 & 3,8 & 2,0 \\
S & 1,0 & 1,1 & 1,2 & 1,4 & - & 1,5 \\
O (по разности) & 6,6 & 5,1 & 4,4 & 4,6 & - & 4,2 \\
Групповой химический состав, \%: & & & & & & \\
углеводороды & 64,6 & 55,4 & 50,6 & 48,4 & 49,3 & 55,0 \\
неароматические & 17,6 & 16,0 & 11,7 & 11,9 & 14,5 & 10,6 \\
$\quad$ ароматические & 47,0 & 39,4 & 38,9 & 36,5 & 34,8 & 44,4 \\
гетероатомные соединения & 35,4 & 44,6 & 49,4 & 51,6 & 50,7 & 45,0 \\
$\quad$ нейтральные & 27,8 & 33,1 & 34,8 & 42,5 & 42,7 & 34,3 \\
кислотные & 7,6 & 11,5 & 14,6 & 9,1 & 8,0 & 10,7 \\
& & & & & &
\end{tabular}

* Вследствие очень малого количества полученной в опыте 1 смолы она детальнее не исследовалась.

Удалением пиритной серы из полукокса в виде сероводорода можно объяснить и своеобразный вид кривой зависимости выхода твердого остатка в расчете на ОВ от состава исходной смеси (рис. 1 , кривая 1 ) выход нелетучего остатка уменьшается за счет этой реакции наиболее существенно при наличии достаточного количества и пирита, и керогена, являющегося источником необходимого для восстановления пирита водорода.

Вышеуказанным обусловлен также характер кривой зависимости выхода сероводорода на исходную смесь от содержания в ней ОВ (рис. 3 , кривая 2): при небольшом содержании пирита в смеси образование серо- 
водорода лимитируется его количеством, при очень высоком содержании - количеством водорода; при этом значительная часть пиритной серы остается в полукоксе. Действительно, содержание серы в твердом остатке составляло в опытах $1-7$ соответственно 47,$0 ; 41,5 ; 33,1 ; 22,6$; 19,$0 ; 13,6$ и $4,0 \%$.

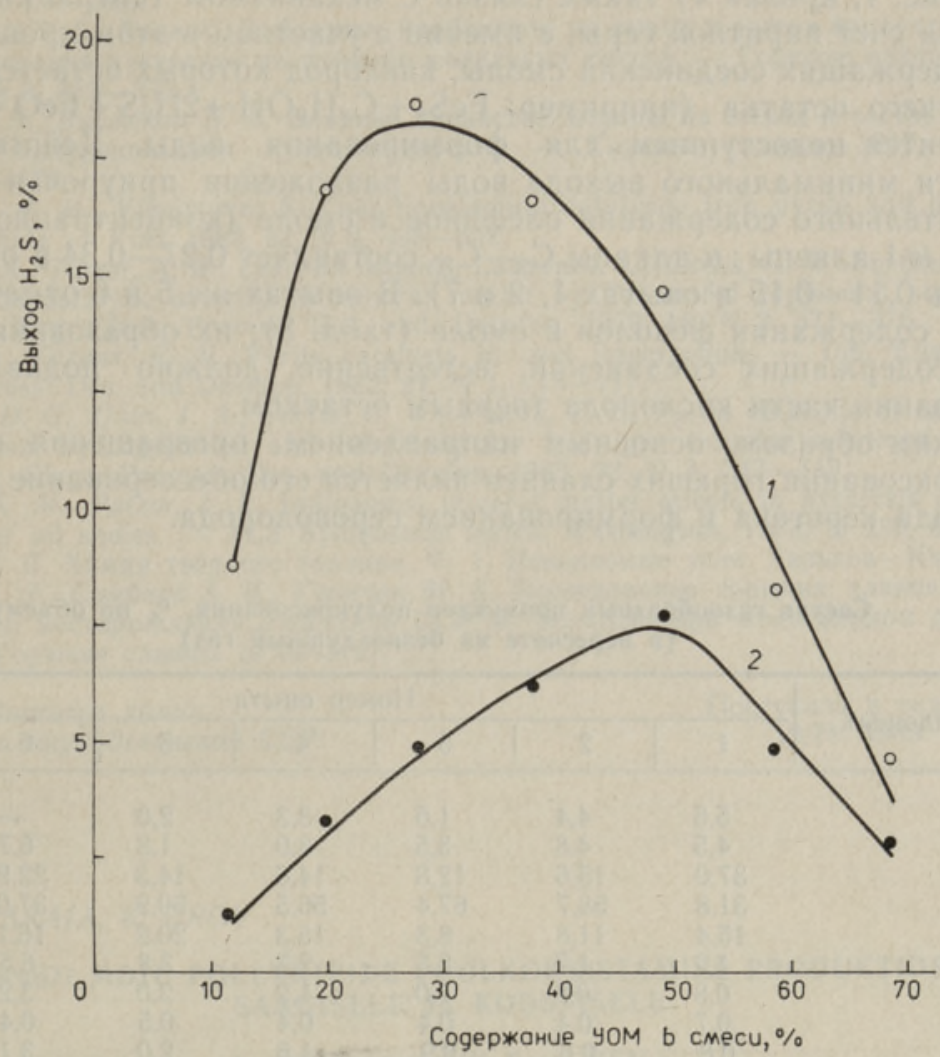

Рис. 3. Зависимость выхода сероводорода от содержания УОМ в исходной смеси: 1 на УОМ, 2 - на исходную смесь.

Сложнее объяснить форму зависимости выхода сероводорода на кероген от его содержания в смеси с пиритом (рис. 3, кривая 1). Снижение выхода сероводорода на ОВ при высоком содержании пирита в смеси (левая часть кривой) можно рассматривать как свидетельство того, что пирит восстанавливается не свободным водородом и другими газообразными продуктами, а водородом более сложных органических соединений смолы, имеющих его подвижные атомы. При высоком содержании минеральных веществ в смеси такие соединения в значительной мере подвергаются вторичным деструктивным реакциям, продукты которых с пиритом уже не взаимодействуют. Действительно, выход двуокиси углерода на ОВ возрастает с $3,4 \%$ в опыте 5 до $13,1 \%$ в опыте 2 , что указывает на интенсивную деструкцию кислородсодержащих соединений смолы при низком содержании керогена в смеси.

$\mathrm{K}$ области максимального выхода сероводорода на ОВ приурочено наивысшее относительное содержание легких парафинов в смоле (концентрационное отношение $\mathrm{H}$-алканы $\mathrm{C}_{9}-\mathrm{C}_{17}$ : $\mathrm{H}$-алканы $\mathrm{C}_{18}-\mathrm{C}_{25}$ составляет $2,4-3,2$ в опытах $2-4$ и лишь $1,0-1,8$ в опытах 1 и $5-7)$, что указывает на имеющее здесь место существенное преобразование первичной 
смолы, по-видимому, в результате взаимодействия с пиритом. Об этом же говорит минимальное значение коэффициентов нечетности $\boldsymbol{H}$-алканов в этом регионе $(0,94$ и 0,96 в опытах 3 и 4 против 1,18 и 1,16 в опытах 2 и 6$)$.

Вероятно, что минимум на кривой выхода пирогенетической воды на ОВ (рис. 1, кривая 4) также связан с механизмом генерации сероводорода за счет пиритной серы, а именно с участием в этом процессе кислородсодержащих соединений смолы, кислород которых остается в составе нелетучего остатка (например: $\mathrm{FeS}_{2}+\mathrm{C}_{x} \mathrm{H}_{y} \mathrm{OH} \rightarrow 2 \mathrm{H}_{2} \mathrm{~S}+\mathrm{FeO}+\mathrm{C}_{x} \mathrm{H}_{y-3}$ ) и становится недоступным для формирования воды. Действительно, к области минимального выхода воды разложения приурочен максимум относительного содержания олефинов в смоле (концентрационное отношение $\boldsymbol{H}$-1-алкены : $\boldsymbol{H}$-алканы $\mathrm{C}_{9}-\mathrm{C}_{20}$ составляет $0,27-0,34$ в опытах $4-6$ и лишь $0,11-0,15$ в опытах 1,2 и 7$)$. В опытах же 5 и 6 отмечается снижение содержания фенолов в смоле (табл. 3 ); их образование как кислородсодержащих соединений, естественно, должно подавляться при связывании части кислорода твердым остатком.

Таким образом, основным направлением превращения пирита при полукоксовании горючих сланцев является его обессеривание с участием водорода керогена и формированием сероводорода.

Таблица 4

Состав газообразных продуктов полукоксования, \% по объему (в пересчете на безвоздушный газ)

\begin{tabular}{l|r|r|r|r|r|r|r}
\hline \multirow{2}{*}{ Компонент } & \multicolumn{7}{|c}{ Номер опыта } \\
\cline { 2 - 8 } & 1 & 2 & 3 & 4 & 5 & 6 & 7 \\
\hline & 5,6 & 4,4 & 1,6 & 3,3 & 2,0 & - & 9,8 \\
$\mathrm{H}_{2}$ & 4,5 & 4,8 & 3,5 & 3,0 & 1,8 & 6,7 & 5,6 \\
$\mathrm{CO}$ & 37,0 & 15,6 & 12,8 & 14,6 & 14,3 & 22,9 & 21,0 \\
$\mathrm{CO}_{2}$ & 31,8 & 58,7 & 67,4 & 56,5 & 50,9 & 37,0 & 26,9 \\
$\mathrm{H}_{2} \mathrm{~S}$ & 15,4 & 11,8 & 8,3 & 15,3 & 20,2 & 16,1 & 18,6 \\
$\mathrm{CH}_{4}$ & 1,9 & 1,7 & 2,5 & 2,5 & 3,8 & 6,5 & 8,0 \\
$\mathrm{C}_{2} \mathrm{H}_{6}$ & 0,8 & 0,8 & 1,0 & 1,2 & 2,0 & 3,2 & 3,3 \\
$\mathrm{C}_{3} \mathrm{H}_{8}$ & 0,7 & 0,4 & 0,4 & 0,4 & 0,5 & 0,4 & 1,2 \\
$\mathrm{C}_{4} \mathrm{H}_{10}$ & 0,8 & 0,6 & 0,9 & 1,5 & 2,0 & 3,1 & 2,1 \\
$\mathrm{C}_{2} \mathrm{H}_{4}$ & 1,1 & 0,9 & 1,0 & 1,1 & 1,9 & 3,2 & 2,3 \\
$\mathrm{C}_{3} \mathrm{H}_{6}$ & 0,4 & 0,3 & 0,6 & 0,6 & 0,6 & 0,9 & 1,2 \\
$\mathrm{C}_{4} \mathrm{H}_{8}$ &
\end{tabular}

Вероятно, что с этим же связано накопление свободной серы при медленном термолизе диктионемового сланца на участках, смежных с очагами его самовозгорания в отвалах: при взаимодействии пирита с продуктами термического разложения керогена генерируется сероводород (табл. 4), из которого в контакте с кислородом воздуха образуется элементная сера.

\section{Выводы}

1. С повышением содержания пирита в смеси с керогеном диктионемового сланца выход смолы полукоксования на органическое вещество снижается, выход газа полукоксования - возрастает.

2. Основным направлением превращения пирита при этом является его обессеривание с участием водорода керогена и формированием сероводорода.

3. Высказано предположение, что накопление свободной серы на участках отвалов диктионемового сланца, смежных с очагами его самовозгорания, является результатом окисления сероводорода, образующегося при взаимодействии содержащегося в сланце пирита с продуктами термического разложения керогена, 


\section{ЛИТЕРАТУ РА}

1. Высоцкая B., Уров К. Влияние минеральной части диктионемового сланща на выход и состав продуктов его термического разложения. - Изв. АН ЭССР. Хим., 1983, 32, № 4, 246-251.

2. Уров К. Э., Высоцкая В. В. Влияние карбонатной породы на выход и состав продуктов полукоксования диктионемового сланца. - Горючие сланцы, 1985, 2, № 2, $170-180$.

3. Высоцкая В. В., Уро К. Э. Влияние карбонатов на выход и состав продуктов полукоксования кукерсита на примере модельных смесей. - Горючие сланцы, 1985 , 3, № 3, 313-319.

4. Уров К. Э., Высоцкая В. В. Влияние глинистой породы на выход и состав продуктов полукоксования сланца-кукерсита. - Горючие сланцы, 1987, 4, № 2, $170-175$.

5. Baldwin, R. M., Vinciquera, S. Coal liquefaction catalysis. Iron pyrite and hydrogen sulphide. - Fuel, 1983, 62, N 2, 498-501.

6. Guin, J. A., Tarrer, A. R., Lee Yun Moung, Lawrence, L., Curtis, C. W. Further studies of the catalytic activity of mineral matter by the model compound studies. Ind. Eng. Chem. Process: Des. and. Develop, 1979, 18, N 3, 371-376.

7. Garg, D., Gizens, E. N. Pyrite catalysis in coal liquefaction. - Ind. Eng. Chem. Process: Des, and Develop, 1982, 21, N 1, 113-117.

8. Brooks, D. G., Guin, J. A., Curtis, C. W., Placek, T. D. Pyrite catalysis of coal liquefaction, hydrogenation and intermolecular hydrogen transfer reactions. - Ind. Eng. Chem. Process: Des. and Develop, 1983, 22, N 3, 343-349.

9. Jeong, K. M., Patzer, J. F. Indigenous mineral matter effects in pyrolysis of Green River oil shales. - ACS Symposium series. Washington, 1983, N 230, 529-542.

10. Крым В. С. Химия твердого топлива. Ч. 1. Ископаемые угли. Харьков-Киев, 1934.

11. Уров К. Э., Сумберг А. И., Гринчак М. Б. Исследование горючих сланцев Джамского месторождения Узбекской ССР. 3. Термолиз при атмосферном давлении. - Горючие сланцы (в печати).
Институт химии
Академии наук Эстонской ССР
Поступила в редакцию 12/IV 1988

\section{VOSSOTSKAJA, K. UROV}

\section{PURIIDI MÕJU POLLEVKIVIDE POOLKOKSISTAMISE PRODUKTIDE SAAGISELE JA KOOSTISELE}

\section{Diktüoneemakilt Eesti NSV-s}

Diktüoneemakilda floteerimisel saadud kerogeeni ja püriidi kontsentraatide segude utmiskatsed näitasid, et püriidi sisalduse kasvades lähtesegus väheneb õlisaagis orgaanilise aine kohta, mineraalse lisandi väävlist ja kerogeeni vesinikust tekib lisakogus väävelvesinikku. On tōenäoline, et elementaarne väävel diktüoneemakilda isesüttimiskollete läheduses tekib püriidi ja õliaurude vahelisel reaktsioonil moodustuva väävelvesiniku oksüdeerumisel õhuhapniku toimel.

\section{VYSOTSKAYA, K. UROV}

\section{THE EFFECT OF PYRITE ON THE YIELD AND COMPOSITION OF OIL SHALE SEMICOKING PRODUCTS}

\section{Dictyonema shale of the Estonian SSR}

By semicoking the concentrate mixtures of kerogen and pyrite obtained on the flotation of dictyonema shale it has been found that with the increasing pyrite content in the initial mixture the oil yield on kerogen decreases, while an additional amount of hydrogen sulfide is formed from the sulfur of mineral part and hydrogen of kerogen. It is probable that the elemental sulfur near the dictyonema shale self-ignition hotbeds results from the air oxygen-caused oxidation of hydrogen sulfide forme ${ }^{*}$ in the reaction of pyrite and oil vapours. 